\title{
Fish Optic Nerve Oligodendrocytes Support Axonal Regeneration of Fish and Mammalian Retinal Ganglion Cells
}

\author{
MARTIN BASTMEYER, ${ }^{1}$ MATHLAS BÄHR, ${ }^{2}$ AND CLAUDIA A.O. STUERMER ${ }^{1}$ \\ ${ }^{1}$ Faculty of Biology, University of Konstanz, 7750 Konstanz, and ${ }^{2}$ Max-Planck-Institut für \\ Entwicklungsbiologie, and Neurologische Universitatsklinik, 7400 Tübingen, Germany
}

KEY WORDS Goldfish, Glial cells, Axonal outgrowth

\begin{abstract}
Segments from adult fish and rat retinae were explanted on myelinmarker expressing oligodendrocytes derived from the regenerating goldfish optic nerve. Fish axons grew in high density and even rat retinal axons regenerated to considerable length on the surface of the fish oligodendrocytes, suggesting that this type of fish glia has axon-growth promoting surface components that exert their influence across species boundaries. One interesting surface component of the fish oligodendrocytes as demonstrated here is the E 587 antigen, which is related to the L1 family of cell adhesion molecules.

In long term cocultures of oligodendrocytes and retinal axons, the fish glial cells were found to enwrap rat axons. This suggests that the oligodendrocytes of the regenerating goldfish optic nerve/tract may, despite striking differences, represent the equivalent to mammalian optic nerve oligodendrocytes.
\end{abstract}

\section{INTRODUCTION}

There is a curious phylogenetic dichotomy between the CNS of anamniotic vertebrates (amphibians and fishes) and the CNS of amniotes (reptiles, birds, and mammals); axon regeneration of the major CNS axon pathways occurs in anamniotes but it is virtually absent in amniotic vertebrates (reviewed in Kiernan, 1979).

If the optic nerve of a frog or a fish is cut, axons originating in the retina will regenerate to reform synaptic connections and restore vision (reviewed in Gaze, 1970). Upon cutting the optic nerve of a rat, the injured axons will form short sprouts for a few days, which, however, fail to elongate (Skene, 1989). Most retinal ganglion cells (RGCs) consequently die and only a few may survive (Bray et al., 1987). However, if the environment of the injured axons is changed by replacing the optic nerve by a peripheral nerve graft (which contains Schwann cells instead of oligodendrocytes), RGC survival is enhanced and several retinal axons regenerate into the peripheral nerve (Bray et al., 1987). Thus, a major impediment for axonal regrowth in mammals seems to be the optic nerve environment, which con- tains reactive astrocytes, oligodendrocytes, and myelin debris (Franklin and Blakemore, 1990).

Oligodendrocytes and the CNS myelin of mammals have proteins that inhibit axon growth upon contact (Bandtlow et al., 1990; Caroni and Schwab, 1988; Fawcett et al., 1989). These inhibitors even act across species boundaries. When fish retinal explants were cocultured with rat oligodendrocytes the fish retinal growth cones collapsed and retracted and when exposed to rat CNS myelin they were unable to elongate (Bastmeyer et al., 1991a). Fish CNS myelin, however, did not elicit such a reaction, in either mammalian (Vanselow et al., 1990) or fish retinal axons (Bastmeyer et al., 1991a). Consistent with these bioassays the inhibitory proteins were not detected in biochemical analyses of fish CNS myelin (Caroni and Schwab, 1988). Accordingly, oligodendrocytes isolated from the goldfish optic nerve/tract are growth permissive such that fish axons in vitro are 
able to grow onto and over these cells (Bastmeyer et al., 1991a). Thus, one reason for the success of axonal regeneration in the fish optic nerve may lie in the growth permissive properties of the fish oligodendrocytes and their myelin.

Another cause may be found in the properties of retinal ganglion cells. In fish, all or almost all retinal ganglion cells regenerate their axons, whereas the percentage of neurons in the rat retina that are able to reextend axons under favorable environmental conditions [into the peripheral nervous system (PNS) nerve graft or on Schwann cells or immature astrocytes] is always small (Bähr and Bunge, 1989, 1990; Bray et al., 1987; Hopkins and Bunge, 1991). More recently it has been found that the fish retinal ganglion cells and their axons re-express a set of growth associated cell surface glycoproteins during retinal axonal regeneration (Bastmeyer et al., 1990a; Paschke et al., 1992; Vielmetter et al., 1991). In normal fish, these proteins are only seen during axonal growth in embryos and larvae and on the small group of new axons that are continuously added to the adult fish optic nerve. One of these molecules, the E 587 antigen, is related to the cell adhesion molecules of the L1 family (Vielmetter et al., 1991). This molecule is of interest in the context of the current study.

The present study extends the analyses of the properties of the fish optic nerve/tract derived glial cells, in particular of the fish oligodendrocytes. In cocultures of fish retinal axons and fish glial cells we observed that the axons elongated preferentially along the oligodendrocytes and their processes, suggesting that these cells are not only not inhibitory but equipped with axongrowth stimulating properties. Our results, in fact, show that axons from retinal explants of goldfish and, moreover, even from adult rats regenerate their axons on the surface of the goldfish oligodendrocytes. The oligodendrocytes exhibit the E 587 antigen on their surface, an L1-like candidate cell adhesion molecule (Vielmetter et al., 1991). This opens the possibility that the E 587 antigen may contribute to the growth permissiveness of the oligodendrocytes' surfaces. We also demonstrate that fish oligodendrocytes in long term cocultures enwrap the rat retinal axons that had grown on their surface in a mode that was described as first steps towards myelination (Remahl and Hildebrand, 1990). This may suggest that the fish oligodendrocytes, despite significant differences, represent equivalents to the mammalian oligodendrocytes.

Preliminary reports of these results were published as abstracts (Bastmeyer et al., 1991b) and in a brief review (Stuermer, 1991).

\section{MATERIALS AND METHODS Preparation of Goldfish Glial Cells}

Fish glial cells were obtained from the regenerating goldfish optic nerve/tract as previously described (Bastmeyer et al., 1991a). In brief, small pieces of the optic nerve/tract (2-3 weeks after optic nerve section) were explanted onto polylysine/laminin-coated coverslips and kept in F-12 medium [Ham's F-12 medium (Gibco) containing $10 \%$ fetal calf serum (FCS), $0.4 \%$ methyl cellulose (Dow), and $50 \mu \mathrm{g} / \mathrm{ml}$ gentamycin] at $28^{\circ} \mathrm{C}$. Glial cells emigrate from the pieces, multiply in culture, and form dense cell clusters by $2-3$ weeks in vitro. The medium was exchanged at 3 day intervals and the cells survived for at least 3-4 months.

\section{Goldfish Retinal Explants}

Goldfish retinal explants were prepared as previously described (Vielmetter and Stuermer, 1989). In brief, the optic nerves of adult goldfish were cut under MS-222 anesthesia. Fourteen to 17 days later the retina was isolated and attached to a nylon filter (Hybond, Amersham). Retina and filter were cut into $300 \mu \mathrm{m}$ wide segments and explanted, ganglion cell layer down, onto the goldfish glial cells. Small metal blocks were placed onto the end of the segments to keep the retina in contact with the substrate. The cocultures were kept in F-12 medium at $28^{\circ} \mathrm{C}$.

\section{Rat Retinal Explants}

Adult rat optic nerves were crushed intraorbitally under chloral hydrate anesthesia $(420 \mathrm{mg} / \mathrm{kg}$ body weight). One week later segments of the isolated retina were prepared as described (Bähr et al., 1988) and explanted onto goldfish optic nerve glial cells. In brief, the isolated retina was whole-mounted onto a semipermeable filter (Millipore) in Hanks' medium and cut into eight sections, which were centered on the optic disk. Retinae were explanted, ganglion cell layer down, onto the fish glial cells and held in place by an overlay of 50 $\mu l$ Matrigel (Dunn). Cocultures were kept in F-12 medium at $28^{\circ} \mathrm{C}$. After $7-12$ days in vitro the cultures were fixed and processed for immunocytochemistry.

\section{Immunocytochemistry}

Fish oligodendrocytes were identified with the monoclonal antibody (MAB) O4 (Sommer and Schachner, 1981) and MAB 6D2 (Jeserich and Rauen, 1990) (kindly provided by $\mathrm{G}$. Jeserich). $\mathrm{O} 4$ is specific for rat oligodendrocytes and O-2A precursor cells (Trotter and Schachner, 1989). 6D2 is directed against the fish specific myelin proteins IP1 and IP2. Both antibodies were used as hybridoma supernatants, 1:2 diluted in medium (Jeserich and Rauen, 1990) or phosphate buffered saline (PBS). Fish astrocytes were identified with a polyclonal rabbit serum against fish glial fibrillary acidic protein (GFAP) (Nona et al, 1989, kindly provided by S. Nona) used at a dilution of 1:1,000. MAB E 587 against an L1-like molecule (Vielmetter et al., 1991) was used as purified IgG at a concentration of $100 \mu \mathrm{g} / \mathrm{ml}$. Goldfish and rat retinal axons were immunostained using $M A B$ 
SMI-31 (Sternberger-Meyer Immunochemicals) against neurofilaments at a dilution of $1: 1,000$.

For immunostaining (except for staining with $\mathrm{O} 4$ ) the cultures were permeabilized with methanol (at $-20^{\circ} \mathrm{C}$ ) and fixed with paraformaldehyde ( $2 \%$ in PBS at room temperature) for 5 min each. After three rinses in PBS ( 5 min each), cultures were treated with primary antibodies, washed in PBS, and incubated with fluorescein (FITC)- or rhodamine isothiocyanate (RITC)-coupled secondary antibodies ( $1 \mathrm{~h}$ at $37^{\circ} \mathrm{C}$ each). All secondary antibodies were obtained from Dianova and used at dilutions of 1:200 in PBS.

For double staining with O4 (mouse IgM) and SMI-31 (mouse $\operatorname{IgG}$ ) the living cultures were first incubated with 04 (1:2 diluted in medium) for $30 \mathrm{~min}$ at $28^{\circ} \mathrm{C}$. After a brief wash in medium they were permeabilized and fixed as described above. They were subsequently exposed to RITC coupled $\mu$-chain specific secondary antibodies for $1 \mathrm{~h}$, washed in PBS, and incubated with SMI-31 for $1 \mathrm{~h}$. After three washes in PBS the cultures were incubated with FITC coupled c-chain specific secondary antibodies.

For double staining with SMI-31 and 6D2 (both mouse $\operatorname{IgG})$ to visualize axons and myelin protein expressing oligodendrocytes, fixed cultures were fïst incubated with SMI-31 and FITC coupled secondary antibodies. After three rinses in PBS they were then exposed to 6D2 and RITC coupled secondary antibodies.

\section{Quantification of Neurite Outgrowth}

Cocultures of rat retinae and goldfish glial cells were fixed and processed for immunocytochemistry after 7 days in vitro. The preparations were viewed at the fluorescence microscope and the longest SMI-31 labeled neurites were measured using a $20 \times$ lens and an eye piece micrometer. Estimate growth rates were obtained by dividing axon lengths by hours in culture. Growth rates were expressed as $\mu \mathrm{m} / \mathrm{h}$ and averaged over all explants that had extended axons. Cocultures of goldfish retinae and goldfish glial cells were fixed and immunostained with MAB SMI-31 after 2 days in vitro. The density of neurite outgrowth did not allow tracing of individual axons. Therefore the distance of the front of the longest axons from the explant was measured and the growth rates extrapolated as described above. These calculations underestimate the actual rates of axon elongation since they do not take into account the lag period preceding the initiation of neurite outgrowth. This method, however, facilitates comparison with earlier studies on axonal regeneration of rat retinal axons on rat Schwann cells (Bähr and Bunge, 1990; Hopkins and Bunge, 1991).

\section{Electron Microscopy}

For electron microscopy, the glial cell cultures were fixed in $2 \%$ glutaraldehyde in 0.1 M PIPES buffer $(\mathrm{pH}$
7.4) for $45 \mathrm{~min}$, postfixed in $1 \% \mathrm{OsO}_{4}$ in $0.1 \mathrm{M}$ cacodylate-buffer ( $\mathrm{pH} 7.4$ ) for $15 \mathrm{~min}$, dehydrated in a graded acetone series, and flat embedded on the coverslip in Vestopal-W (Serva). Interesting regions were selected under the light microscope, excised, removed from the coverslip, and re-embedded. Ultrathin sections from trimmed blocks of $300 \times 50 \mu \mathrm{m}$ were double stained with lead citrate and uranyl acetate and viewed in a Zeiss EM-9.

\section{RESULTS \\ Characterization of Goldfish Glial Cells}

The fish optic nerve/tract glial cells in culture consist of mainly two types, both of which proliferate in culture. The first type are cells of elongated shape, the goldfish oligodendrocytes (Bastmeyer et al., 1991a), which are recognized by the antibody O4 (Sommer and Schachner, 1981) and the antibody 6D2 against the fish myelin proteins IP1 and IP2 (Jeserich and Rauen, 1990). These cells are migratory and also assemble to form a network-work like array. The other group consists of compact cells that are GFAP positive but $\mathrm{O} 4$ negative. These cells represent fish astrocytes (Hoppe et al., 1991). Astrocytes usually occur in separate clusters. When the cell density in the culture increases, oligodendrocytes apparently migrate into the astrocyte-rich clusters, because 6D2-positive oligodendrocytes processes were found among the astrocytes in 3 week and older but not in younger cultures. Astrocytes, however, were rarely noted outside their clusters. Thus, large territories of only oligodendrocytes are interrupted by smaller fields containing astrocytes and some oligodendrocytes. Although both glial cells mix in the clusters, we will refer to the grouped astrocytes for simplicity as astrocyte-rich clusters.

\section{Regenerating Fish and Rat RGC Axons Elongate on Goldfish Optic Nerve/Tract Oligodendrocytes}

When segments of adult fish retina were explanted onto these fish glial cells, axons extended vigorously on the fish oligodendrocytes, reaching a density that has never been observed on any other substrate tested so far, including laminin (Vielmetter et al., 1990). Their estimated growth velocity was $80 \pm 10 \mu \mathrm{m} / \mathrm{h}$, with a range of 70 to $120 \mu \mathrm{m} / \mathrm{h}$. Growth cones were often seen to follow the processes of the oligodendrocytes, suggesting that the surfaces of this type of fish glial cell represent a favorable substrate for growth cone adhesion and elongation (Fig. 1a-c). Only a few axons crossed the astrocyte-rich clusters. In fact, as axons reached a region between oligodendrocytes and the astrocyte-rich clusters, the axons turned away from the astrocyte cluster and continued their growth on the oligodendrocytes (Fig 1d-f). These observations indicate that axons prefer the oligodendrocytes over astrocytes as a substrate for their growth. 

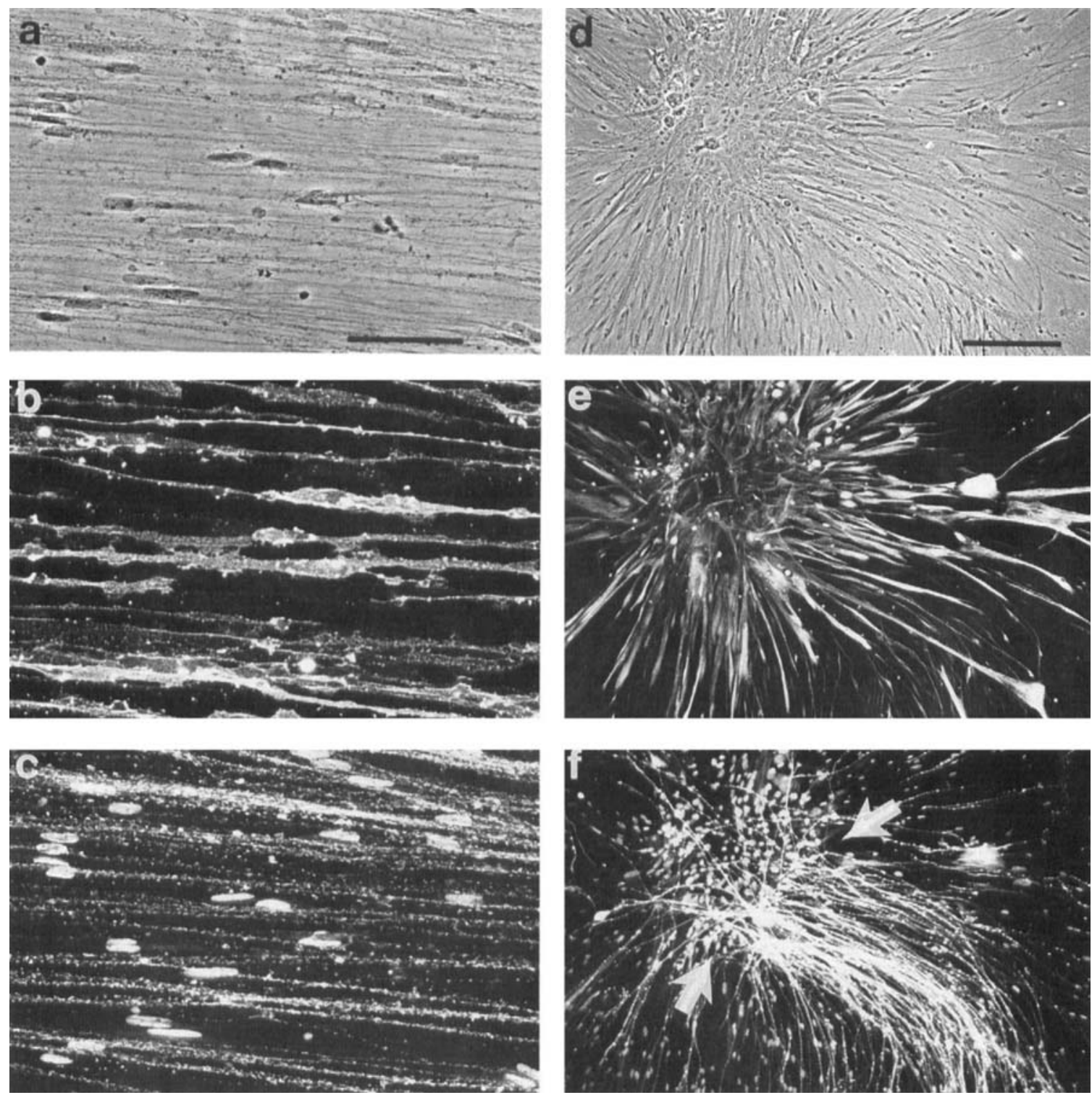

Fig. 1. Interaction of goldfish retinal axons with goldfish optic nerve/ tract glial cells. $a, b$, and $c$ show the same segment of the coculture. a: Phase contrast photomicrograph of fish retinal axons growing on fish oligodendrocytes. $b$ : The oligodendrocytes are labeled by the antibody O4. c: The retinal axons growing on the fish oligodendrocytes are distinguished by staining them with SMI 31 against netrofilaments. SMI binds unspecifically to cell nuclei. Calibration bar in a applies to $a, b$, and $c=100 \mu \mathrm{m} . d, e$, and f represent identical segments of the coculture. d: Phase contrast micrograph of an astrocyte cluster with

Based on our earlier findings that the inhibitory molecules of mammalian oligodendrocytes (Caroni and Schwab, 1988) exert their negative influence across species boundaries and impair fish retinal growth cone elongation (Bastmeyer et al., 1991a), we asked whether the growth stimulating properties of the fish oligodendrocytes would positively affect mammalian RGC axons. We therefore cocultured fish oligodendrocytes with rat retinal explants and tested whether the fish glial

oligodendrocytes inserted between the astrocytes, and retinal axons extending from an explant (out of view in the right hand corner). The glial cells were exposed to the antiserum against GFAP, which labels the fish astrocytes. f: Retinal axons, revealed by the neurofilament staining, grow along oligodendrocytes towards the astrocyte cluster. Where astrocytes lie more closely together most of the axons change their original growth direction (arrows). As in c, unspecific staining of the nuclei by SMI 31. Calibration bar in d applies to $\mathrm{d}$, $\mathrm{e}$, and $\mathrm{f}=200 \mathrm{\mu m}$.

cells would trigger axon regeneration of RGCs of adult rats.

For coculturing retinal explants from a warmblooded vertebrate (the rat) and glial cells from a coldblooded animal (the fish), the fish glial cells and the rat retinae were kept on glass coverslips and at a compromise temperature of $28^{\circ} \mathrm{C}$. Under such culture conditions explants from adult rat retinae did not extend axons on laminin coated glass coverslips. However, when rat ret- 
inal explants were placed onto the carpet of fish oligodendrocytes, axons grew to considerable density and reached a length of 4-5 mm after 7 days in vitro (Fig. 2). The growth velocity of the longest axons of 12 explants was estimated to be at least $22 \pm 5.2 \mu \mathrm{m} / \mathrm{h}$, with a range of 13 to $29 \mu \mathrm{m} / \mathrm{h}$. The regenerating rat axons grew like fish axons on and in close association with the surfaces of the fish oligodendrocytes and these cells expressed myelin marker proteins (Fig. 3). Rat axons hardly ever crossed oligodendrocyte-sparse or oligodendrocyte-free regions and only a few axons appeared on fish astrocyte-rich clusters (Fig. 2). Like fish retinal axons, regenerating rat retinal axons also turned when encountering fish astrocyte-rich clusters and continued their growth on the fish oligodendrocytes (Fig. 2). Thus, fish oligodendrocytes promote rat RGC axon regeneration in vitro. They even do so under culture conditions that are suboptimal for rat retinae. This conclusion is based on observations of 61 rat retinal explants in five separate experiments. Fifteen of these explants exhibited massive ( $>50$ axons) and 29 moderate (20-50 axons) outgrowth of axons while 17 explants showed no outgrowth. The failures are most likely attributable to the fact that the retina did not adhere properly to the substrate. These results suggest that fish oligodendrocytes must carry molecules on their surface that favor the regrowth of ganglion cell axons not only of fish but even of the rat.

\section{Ensheathment of Rat RGC Axons by Fish Oligodendrocytes}

To investigate whether fish oligodendrocytes would eventually ensheath the axons that have grown on their surface, oligodendrocytes and retinal explants were cocultured for 4 weeks with rat axons, and 7 weeks with fish axons, and examined electron microscopically. The electron micrograph in Figure 4 shows a fish glial cell with ultrastructural characteristics of oligodendrocytes (Wolburg, 1978). The cell has a dark cytoplasm, an indented nucleus, and does not exhibit intermediate filaments. The cell was surrounded neither by a basal laminan or collagen fibrils, which characterize Schwann cells (Peters et al., 1991). The cell entirely surrounded the axons; moreover, vermicular processes known to be typical for oligodendrocytes that begin to ensheath axons (Knobler et al., 1974) are associated with the circumference of the rat retinal axons. In the blocks selected from this and age matched cocultures such configurations were met repeatedly. These morphological features are interpreted to mean that fish oligodendrocytes invest the rat axons. In cocultures of fish glial cells and fish axons, axon ensheathment by oligodendrocytes was not seen.

These results indicate, first, that oligodendrocytes of fish are susceptible to properties of rat retinal axons, inducing rat axon ensheathment by the fish glial cells, and second, that the fish glial cells we have termed oligodendrocyte-like cells in earlier studies (Bastmeyer et al., 1991; Hoppe et al., 1991) may indeed represent the equivalent to mature mammalian oligodendrocytes (see Discussion).

\section{Expression Pattern of the E 587 Antigen on Fish Oligodendrocy tes}

In an earlier study (Vielmetter et al., 1991) we have demonstrated that a $200 \mathrm{kd}$ cell surface glycoprotein, the $\mathrm{E} 587$ antigen, is re-expressed by all axons during retinal axonal regeneration after optic nerve transection. When E 587 was applied to the fish glial cells in culture, it stained the surface of the oligodendrocytes in a striking pattern. Astrocytes in these clusters appeared weakly labeled by $\mathrm{E} 587$, but the staining on astrocytes was difficult to visualize since the bright staining on the oligodendrocyte processes in the astrocyte-rich clusters obscured the astrocyte cell surfaces. Individual astrocytes that were occasionally found at the outer margins of the network-like carpet of the oligodendrocytes showed a sparse and punctate E 587 staining on their surface. Individual oligodendrocytes without contacts to other cells exhibited a rather homogeneous labeling on their surface. However, where two of these cells had overlapping processes, the immunofluorescence was accumulated at these contact patches (Fig. 5c). The increased intensity of fluorescence did not appear to be simply an additive effect of the fluorescence on the cells surfaces that overlapped, but seemed rather due to a clustering of the immunofluorescent components at these sites. To confirm this impression glial cells were double labeled with O4 (Fig. 5b) and E 587 (Fig. 5c) and both staining patterns compared. Moreover, using a SIT-camera mounted to the microscope and an image processor with an intensity measuring system, the 04 and E 587 immunofluorescence was determined separately. The parts of the cells that were not in contact with the other cell and the contact sites were scanned. 04 labeled the entire surface of the cells and was twofold brighter than the rest of the cells at contact patches of two cells. In contrast to the $\mathrm{O} 4$ positivity, E 587 staining appeared reduced over most of the cells except for the contact patches, giving the impression that the antigen had accumulated at these contact patches. The intensity measurements indicated a 3.5-fold higher E 587 fluorescence at contact patches as opposed to the remaining cell surface.

These results suggest that the oligodendrocytes actively accumulate the $\mathrm{E} 587$ antigen at sites where processes of two cells overlap. The presence of the E 587 antigen on both axons (Vielmetter et al., 1991) and oligodendrocytes leads to the speculation that this candidate cell adhesion molecule may participate in the interaction of the axons with these cells.

\section{DISCUSSION}

The major result of the foregoing study is the finding that the surface of fish optic nerve/tract derived oligodendrocytes supports the growth of regenerating axons 

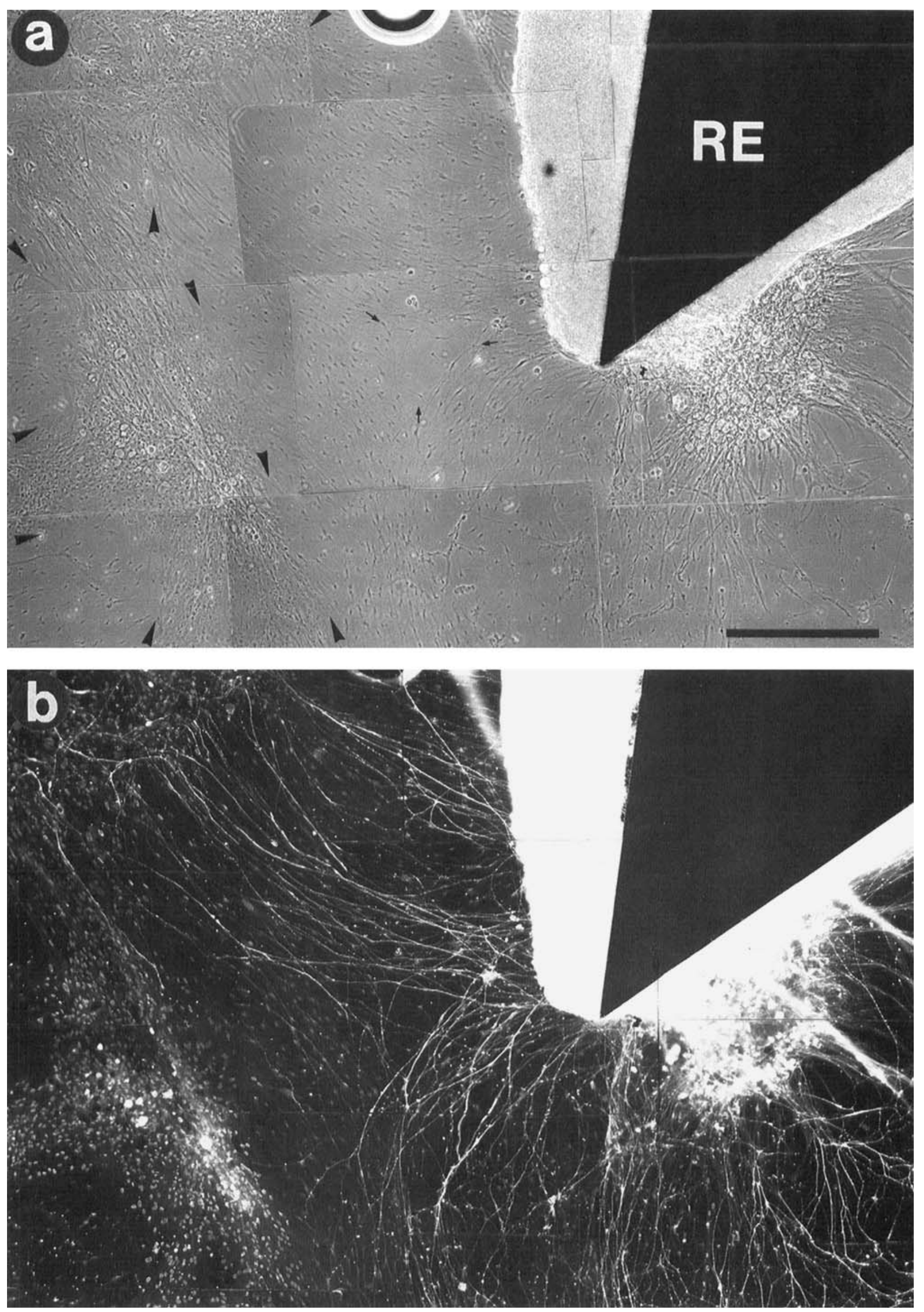

Fig. 2. 

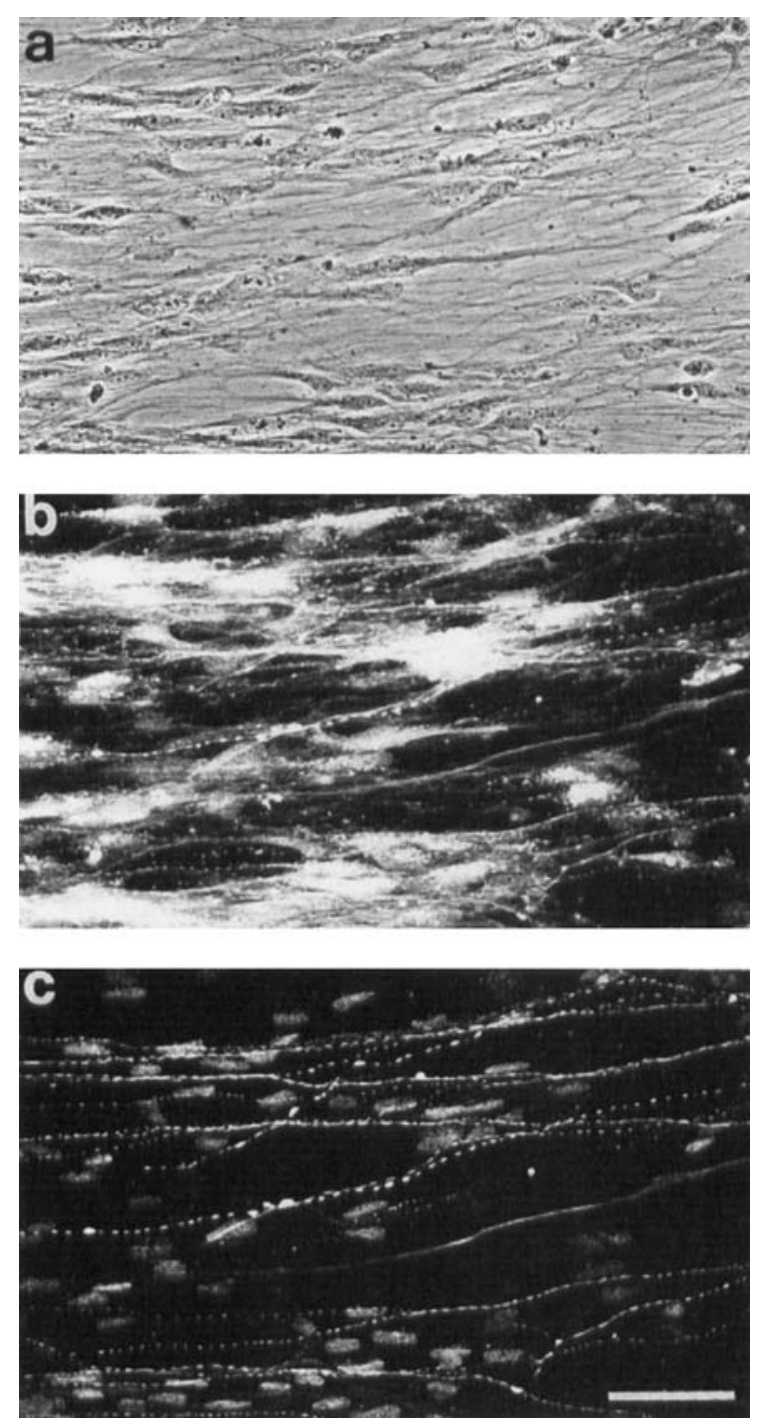

Fig. 3. Association of rat retinal axons with fish oligodendrocytes. a, b, and $\mathbf{c}$ show the same segment of a coculture. a: Phase contrast micrograph of fish oligodendrocytes and rat axons. b: The fish oligodendrocytes are labeled by the antibody 6D2 against fish myelin proteins. c: Rat axons, revealed by neurofilament staining with SMI 31, follow the surfaces of the fish oligodendrocytes. Staining of nuclei to nonspecific binding of SMI 31. Calibration bar in $c$ applies to $a, b$, and $c$ $100 \mu \mathrm{m}$.

Fig. 2. A segment of the retina of an adult rat, explanted onto fish glial cells. Photomicrograph of the coculture in phase contrast (a) and after staining the axons with the antineurofilament antibody SMI 31 (b). a: Arrowheads mark boundaries between pure oligodendrocyte territories and clusters of astrocytes, into which a few oligodendrocytes have penetrated. The small arrows point to a cell-free region. The cells in the lower right corner are glial cells that emigrated from the rat retinal explant. RE, Rat retinal explant attached to a filter (black triangle). $b$ : The rat retinal axons extend along the fish oligodendro* cytes and are seen to follow into the orientation that the elongated oligodendrocytes exhibit. The rat axons tend not to cross the glial cell-free region and only a few grow onto the fish astrocyte cluster. As in Figure 1c and $f$, nonspecific staining of the nuclei of the cells by SMI 31 . Calibration bar in a applies to $\mathrm{a}$ and $\mathrm{b}$ and $=500 \mu \mathrm{m}$. from fish retina explants, and that these fish glial cells exert a striking growth promoting influence on rat retinal ganglion cells. Retinal explants from adult rats regenerate axons in considerable density and length on the fish oligodendrocytes, and this despite suboptimal culture conditions for the mammalian tissue. There is a striking difference between the oligodendrocytes of the regenerating fish optic nerve/tract and mammalian oligodendrocytes with respect to axon-oligodendrocyte interaction. Oligodendrocytes of the mammalian CNS and CNS myelin inhibit the growth of axons, when axons meet these cells or their myelin (Schwab and Caroni, 1988). Fish oligodendrocytes and fish CNS myelin lack the axon-growth inhibitors such that axons freely cross these cells and the myelin (Bastmeyer et al., 1991a). The present study took advantage of the fact that oligodendrocytes from the regenerating fish optic nerve/tract multiply in culture and form a network-like carpet. The growth stimulating properties on the oligodendrocyte surfaces affect fish retinal axons and also, across species boundaries, the ganglion cells of adult rats.

This result is striking in so far as it is known that most mammalian CNS neurons including the retinal ganglion cells fail to regenerate their axons spontaneously upon injury (see Skene, 1989, for review). Only under special conditions, i.e., in replacing the optic nerve by a peripheral nerve graft with living Schwann cells, does a fraction of rat $R G C$ s regrow their axons into the graft (Bray et al., 1987). Rat retinal explants in culture can also be triggered to extend axons when they are offered Schwann cells (Bähr and Bunge, 1989; Hopkins and Bunge, 1991) or astrocytes of neonatal rats as a substrate (Bähr and Bunge, 1990). In fact, the length of the rat axons and their estimated growth velocity was, in fish oligodendrocytes, similar to the values obtained on mammalian Schwann cells (Bähr and Bunge, 1989; Hopkins and Bunge, 1991) and astrocytes of neonatal rats (Bähr and Bunge, 1990). While those experiments were carried out under culture conditions that are optimal for adult rat retina explants (i.e., at $37^{\circ} \mathrm{C}$ on Petriperm dishes that allow a better diffusion of oxygen) (Bähr et al., 1988), the assays presented here used a compromise coculture situation compatible with the needs of a warmblooded and a coldblooded vertebrate. Since adult rat RGCs would fail to regenerate axons under such conditions in the absence of fish oligodendrocytes, we conclude that the growth stimulating effect of fish oligodendrocytes must be at least equal to that of mammalian Schwann cells and immature astrocytes or even exceed it.

A further difference between mammalian oligodendrocytes and oligodendrocytes from the regenerating fish optic nerve/tract, is the expression of an L1-like molecule on fish oligodendrocytes (Vielmetter et al., 1991). Molecules of the L1-like family are known to support the growth of axons that also express these adhesive molecules (Chang et al., 1990; Lemmon et al., 1989; Seilheimer and Schachner, 1988). L1 in mammals is on Schwann cells (Seilheimer and Schachner, 1988) and astrocytes (Ard et al., 1991; Bartsch et al., 


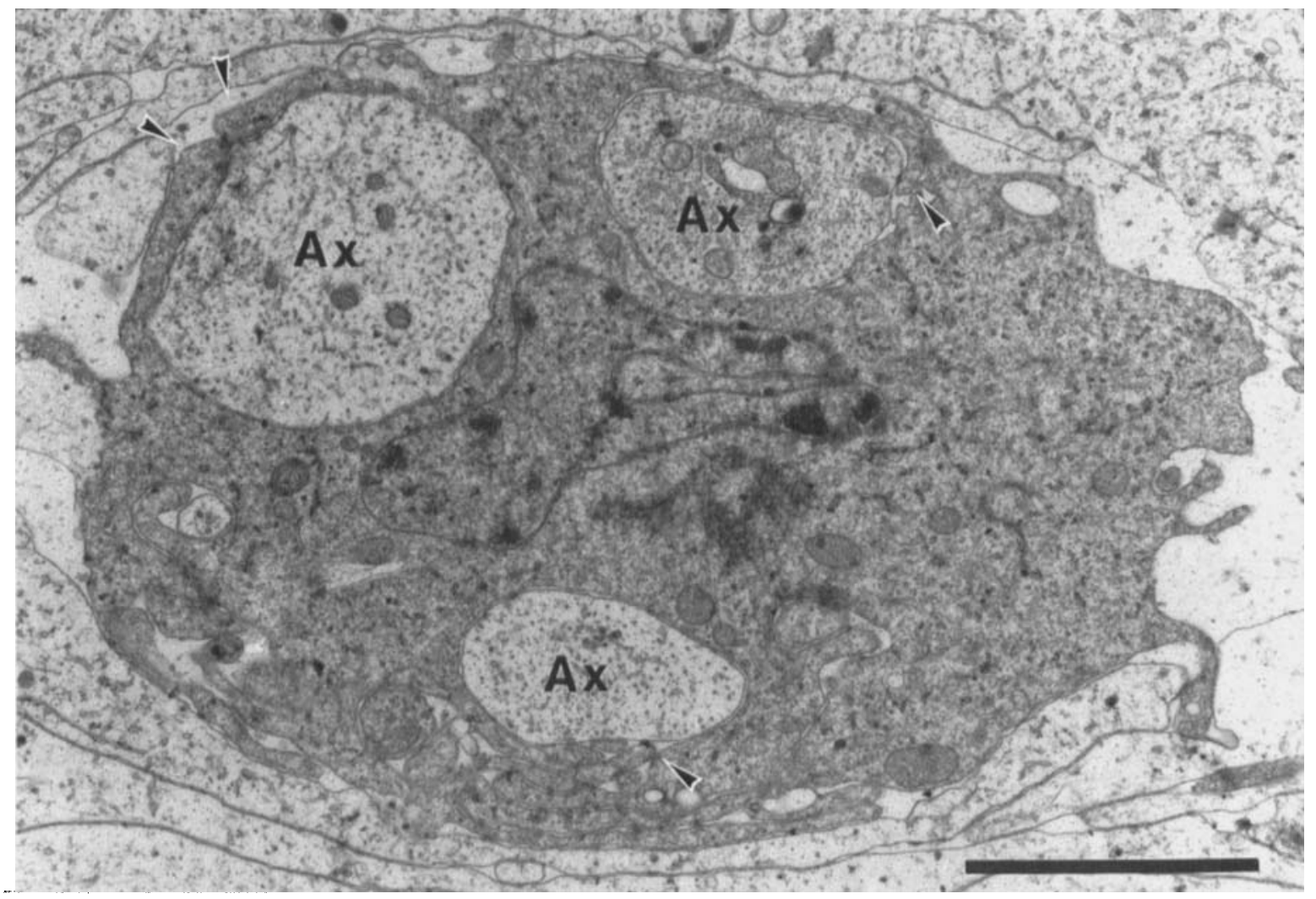

Fig. 4. Fish oligodendrocyte ensheathing rat retinal axons. This electron micrograph was taken from a 4 week old coculture of fish glial cells and rat retinal axons. The dark cytoplasm and the indented nucleus identify the cell as an oligodendrocyte. The cell has totally surrounded the axons (Ax) and has formed vermicular processes (three of which are marked by arrowheads) around the axons. The axons are identified by their electron light cytoplasm, neurofilaments and microtubules, and absence of ribosomes. Calibration bar $=2 \mu \mathrm{m}$.
1989) but is not found on oligodendrocytes of most areas of the CNS. Only axon ensheathing glia cells in the mammalian olfactory system have recently been demonstrated to be L1 positive (Barnett and Noble, 1991), and these cells allow the growth of axons of the continuously renewing neurons in the olfactory system.

Reasons for considering the elongated fish glial cells as oligodendrocytes are: 1) that these cells are recognized by the antibody O4 (Sommer and Schachner, 1981) that was found to be specific for mammalian glial cells of the O-2A lineage (Raff et al., 1983); 2) that they are recognized by MAB $6 \mathrm{D} 2$ directed against the fish myelin proteins IP $1 / 2$ (Jeserich and Rauen, 1990); 3) that they enclose axons growing on their surface much like myelin-sheath forming oligodendrocytes or Schwann cells at the onset of myelination (Remahl and Hildebrand, 1990); and 4) that they do not exhibit a basal lamina or collagen fibrils as typical for Schwann cells (Peters et al., 1991).

O4-positive mammalian oligodendrocytes acquire $\mathrm{O} 1$ (Galc) positivity during further steps of maturation (Sommer and Schachner, 1982). In the culture conditions described here and in earlier publications (Bastmeyer et al., 1991a; Hoppe et al., 1991), the oligodendrocytes of the regenerating fish optic nerve/tract were not labeled by $\mathrm{O} 1$ (GalC) antibodies. Therefore we have previ- ously used the term oligodendrocyte-like cells for these fish glial cells. However, the present finding that these fish glial cells invest axons in the cocultures is one indication that they indeed represent the equivalent of mature mammalian oligodendrocytes. This is supported by very recent observations that some fish oligodendrocytes exhibited $\mathrm{O} 1$ (GalC) positivity after a modification of the culture conditions was introduced (Bastmeyer, unpublished results). Although we did not find enwrapment of fish retinal axons by fish oligodendrocytes, the observation that oligodendrocytes formed long processes in close association with numerous axonal profiles suggests that they may have performed the first of the many steps towards myelination. A recent study (Remahl and Hildebrand, 1990) has, in fact, demonstrated similar associations of oligodendrocytes with axons in developing mammals, preceding the enwrapment and myelination of individual axons. Why fish oligodendrocytes invested regenerating rat but not fish axons is not yet clear to us. Either we have not yet found the appropriate age of the cells and the stages at which glial cell investment of fish axons begins or the culture conditions are, for reasons that we do not understand, inappropriate for the fish axons, such that they may fail to produce the signals necessary for the onset of myelination by the glial cells. 

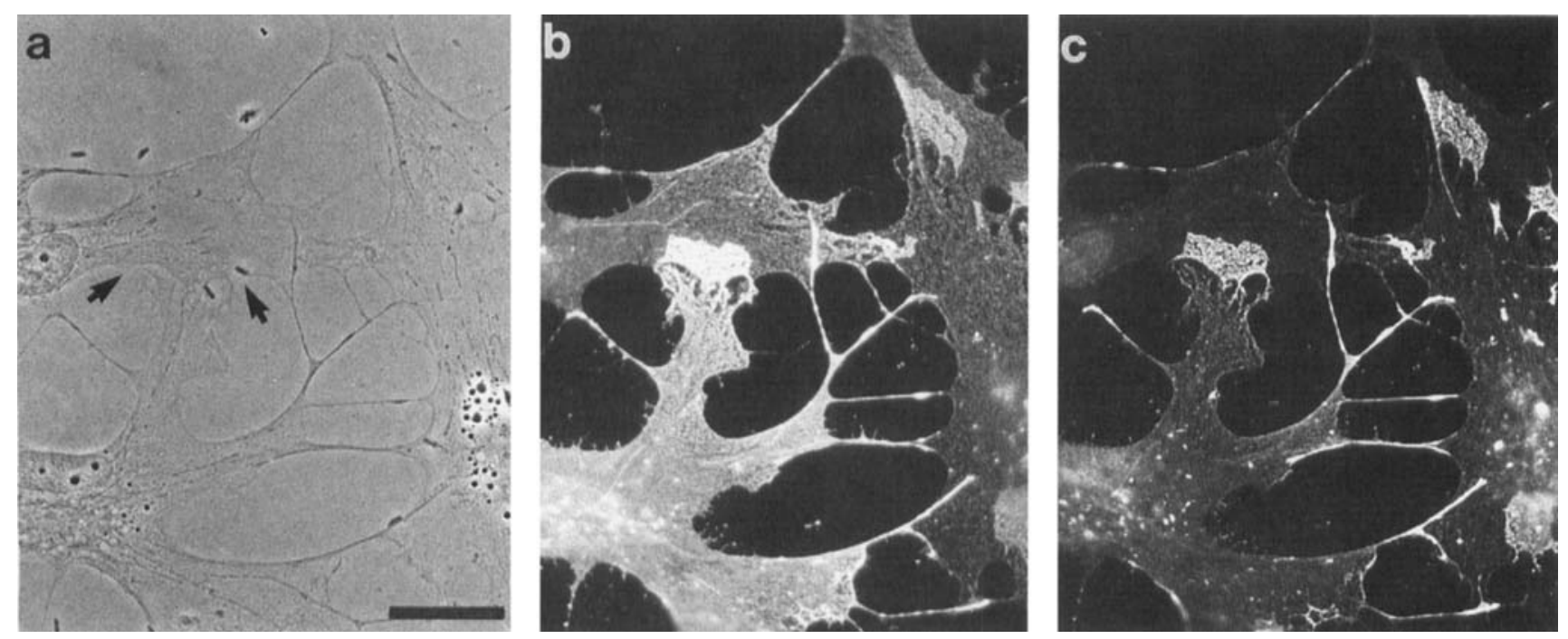

Fig. 5. The pattern of E 587 staining on fish oligodendrocytes. a, b, and c show the same segment of the glial cell culture a: Phase contrast micrograph. Arrows point to one of the overlapping processes of oligodendrocytes. b, c: Staining of the oligodendrocytes with $\mathrm{O} 4$ (b) and $\mathrm{E} 587$ (c). 04 labels the entire surface of the glial cells, whereas $\mathrm{E} 587$ appears predominantly accumulated at contact patches between two cells. Calibration bar in a applies to $a, b$, and $c$ and $=20 \mu \mathrm{m}$.

Oligodendrocytes are readily distinguished from fish astrocytes, which contain a large number of anti-GFAPpositive glial filaments, are not stained by either $\mathrm{O} 4$ or $6 \mathrm{D} 2$, and exhibit a flat compact morphology that contrasts to the elongated shape of fish oligodendrocytes. The fact that astrocytes stay close together in clusters and do not spread into the oligodendrocyte territories was useful in our study since it enabled us to evaluate axon growth over pure oligodendrocyte regions. Although oligodendrocytes invaded into astrocyte-rich clusters, both fish and rat axons appeared to prefer pure oligodendrocyte territories over astrocyte-rich clusters for their growth. This finding suggests that these fish astrocytes represent less favorable substrates than oligodendrocytes. Whether fish astrocytes in these clusters would carry the E 587 antigen on their surfaces could not be decided unambiguously because the oligodendrocytes and their processes obscured most of the astrocyte surfaces. It has been reported that mammalian astrocytes involved in scar formation after optic nerve injury lack axon growth promoting properties and thus differ from immature astrocytes (Bovolenta et al,, 1991; Kalderon, 1988; Liuzzi and Lasek, 1987). One possibility would be that the fish astrocytes in our cultures resemble the scar forming astrocytes in mammals, although astrocytic scars do not exist in injured and regenerating fish optic nerves.

The results of our study do, however, imply that fish oligodendrocytes must express growth stimulating molecules on their surface. The observation that both regenerating fish axons (Vielmetter et al., 1991) and the oligodendrocytes in vitro express the $\mathrm{E} 587$ antigen opens the possibility that this candidate cell adhesion molecule is involved in axon elongation on these glial cells.
Ongoing studies have shown that the E 587 antigen also accumulates at contact sites between regenerating fish axons and fish oligodendrocytes (Bastmeyer et al., 1991b). However, whether the E 587 antigen serves indeed as a growth promoting molecule remains to be decided in functional test with function blocking antibodies. The striking accumulation of the $\mathrm{E} 587$ antigen at cell-cell contact sites strongly suggests that this antigen also participates in the interaction of the cells with one another.

If $\mathrm{E} 587$ is involved in stimulating axon outgrowth and elongation it is probably not the only molecule on the oligodendrocytes that has such a function. The fish myelin proteins IP1/2 (Jeserich and Rauen, 1990) may also promote axonal growth. IP1/2 have been demonstrated to be related to the PNS myelin protein $P_{0}$ (Schliess and Stoffel, 1991). $P_{0}$, a member of the class of cell adhesion molecules, is capable of supporting axonal elongation under special conditions (Schneider-Schaulies et al., 1990). Furthermore, when axons grow on mammalian Schwann cells, several molecules have been found to be important for this process, L1 being only one of them (Kleitmann et al., 1988).

Growth stimulation by fish oligodendrocytes is not limited to fish and rat $\mathrm{RGC}$ axonal regeneration; fish oligodendrocytes also elicit massive outgrowth of embryonic day 6 chick retinae in coculture conditions similar to those described for rats (Bastmeyer et al., 1990b). These findings suggest that the molecules on fish oligodendrocyte surfaces are effective for regenerating as well as for embryonic axons.

A question that remains to be solved is whether these oligodendrocytes that exert their function in vitro are present in the fish optic nerve/tract in vivo when fish 
retinal axons regenerate and whether they are used as substrates by the regenerating growth cones. The cells in culture are derived from regenerating optic nerves' tracts, indicating that these cells or their precursors are present in vivo, but cells can alter their properties depending on factors in the medium or special culture situations. We have observed regenerating growth cones in the nerve in direct touch with myelin and with a cell type whose identity was ambiguous (Strobel and Stuermer, 1991). By ultrastructural characteristics and descriptions of glial cells on the EM level in mammals, this cell type was either an oligodendrocyte precursor or a microglial cell. Thus a clear answer to the situation in vivo awaits the outcome of current studies.

\section{ACKNOWLEDGMENTS}

We wish to thank John Scholes for corrections to the manuscript and for stimulating discussions. We also thank U. Topel for their excellent technical assistance. This work was supported by the DFG, SFB 156, TPC6 to C.A.O.S. and by the Hertie-Stiftung.

\section{REFERENCES}

Ard, M.D., Bunge, M.B., Wood, P.M., Schachner, M., and Bunge, R.P. (1991) Retinal neurite growth on astrocytes is not modified by extracellular matrix, anti-L1 antibody, or oligodendrocytes. Glia, 4:7082.

Bâhr, M. and Bunge, R.P. (1989) Functional status influences the ability of Schwann cells to support adult rat retinal ganglion cell survival and axonal regrowth. Exp. Neurol., 106:27-40.

Bähr, M. and Bunge, R.P. (1990) Growth of adult rat retinal ganglion cell neurites on astrocytes. Glia, 3:293-300.

Bähr, M., Vanselow, J., and Thanos, S. (1988) In vitro regeneration of adult rat ganglion cell axons from retinal explants. Exp. Brain Res., $73: 393-401$

Bandtlow, C., Zachleder, T., and Schwab, M.E. (1990) Oligodendrocytes arrest neurite growth by contact inhibition. J. Neurosci., 10: 3837-3848.

Barnett, S.C. and Noble, M. (1991) Identification of a novel glial cell isolated from the olfactory bulb by fluorescence activated cell sorting. Eur. J. Neurosci. Suppl., 4:102.

Bartsch, U., Kirchhoff, F, and Schachner, M. (1989) Immunohistochemical localization of the adhesion molecules L1, N-CAM, and MAG in the developing and adult optic nerve of mice. J. Comp. Neurol, 284:451-462.

Bastmeyer, M., Schlosshauer, B., and Steurmer, C.A.O. (1990a) The spatiotemporal distribution of N-CAM in the retinotectal pathway of adult goldfish detected by the monoclonal antibody D3. Development, 108:299-311.

Bastmeyer, M., Vielmetter, J., Jeserich, G., and Stuermer, C.A.O. (1990b) Growth of retinal axons on goldfish optic nerve oligodendrocytes in vitro. Soc. Neurosci. Abstr., 16:1006.

Bastmeyer, M., Beckmann, M., Schwab, M.E., and Steurmer, C.A.O. (1991a) Growth of regenerating goldfish axons is inhibited by rat oligodendrocytes and CNS myelin but not by goldfish optic nerve tract oligodendrocytelike cells and fish CNS myelin. $J$. Neurosci., 11:626-640.

Bastmeyer, M., Bähr, M., and Stuermer, C.A.O. (1991b) Growth of adult rat retinal axons on goldfish oligodendrocytes in vitro, Soc. Neurosci. Abstr., 17:211.

Bovolenta, P., Wandosell, F., and Nieto-Sampedro, M. (1991). Central neurite outgrowth over glial scar tissue in vitro. In: The Nerve Growth Cone. P.C. Letourneau, S.B. Kater, E.R. Macagno, eds., Raven Press, New York, pp. 477-488.

Bray, G.M., Villegas-Perez, M.P., Vidal-Sanz, M., and Aguayo, A.J. (1987) The use of peripheral nerve grafts to enhance neuronal sur- vival, promote growth and permit terminal reconnections in the central nervous system of adult rats. J. Exp. Biol., 132:5-19.

Caroni, P. and Schwab, M.E. (1988) Two membrane protein fractions from rat central myelin with inhibitory properties for neurite growth and fibroblast spreading. $J$. Cell Biol., 106:1281-1288.

Chang, S., Rathjen, F, and Raper, J.A. (1990) Neurite outgrowth promoting activity of $\mathrm{G} 4$ and its inhibition by monoclonal antibodies. J. Neurosci. Res, 25:180-186.

Fawcett, J.W., Rokos, J., and Bakst, I. (1989) Oligodendrocytes repel axons and cause axonal growth cone collapse. J. Cell Sci., 92:93100.

Franklin, R.J.M. and Blakemore, W.F. (1990) The peripheral nervous system-central nervous system regeneration dichotomy: A role for glial cell transplantation. J. Cell Sci., 95:185-190.

Gaze, R.M. (1970) The Formation of Nerve Connections. Academic Press, London.

Hopkins, J.M. and Bunge, R.P. (1991) Regeneration of axons from adult rat retinal ganglion cells on cultured Schwann cells is not dependent on basal lamina. Glia, 4:46-55.

Hoppe, D., Bastmeyer, M., Von Blankenfeld, G., Kettenmann, H., and Stuermer, C.A.O. (1991) Two populations of glial cells from fish optic nerve/tract with distinct electrophysiological properties. Exp. Brain Res, , 87:383-388.

Jeserich, G. and Rauen, T. (1990) Cell cultures enriched in oligodendrocytes from the central nervous system of trout in terms of phenotypic expression exhibit parallels with cultured rat Schwann cells. Glia, 3:65-74

Kalderon, N. (1988) Differentiating astroglia in nervous tissue histogenesis/regeneration: Studies in a model system of regenerating peripheral nerve, $J$. Neurosci. Res., 21:501-512.

Kiernan, J.A. (1979) Hypotheses concerned with axonal regeneration in the mammalian nervous system. Biol. Rev., 54:155-197.

Kleitman, N., Wood, P., Johnson, M.I., and Bunge, R.P. (1988) Sehwann cell surfaces but not extracellular matrix organized by Schwann cells support neurite outgrowth from embryonic rat retina. $J$. Neuro sci., 8:653-663.

Knobler, R.L., Stempak, J.G., and Laurencin, M. (1974) Oligodendroglial ensheathment of axons during myelination in the developing rat central nervous system. A serial section electron microscopical study. J. Ultrastruct. Res. 49:34-49.

Lemmon, V., Farr, K.L., and Lagenaur, C. (1989) L1-mediated axon outgrowth occurs via a homophilic binding mechanism. Neuron, $2: 1597-1603$.

Liuzzi, F.J. and Lasek, R.J. (1987) Astrocytes block axonal regeneration in mammals by activating the physiological stop pathway. Science, 237:642-645.

Nona, S.M., Shehab, S.A.S., Stafford, C.A., and Cronly-Dillon, J.R (1989) Glial fibrillary acidic protein (GFAP) from goldfish: Its localisation in visual pathway. Glia, 2:189-200.

Paschke, K.A. Lottstpeich, F and Stuermer, C.A.O (1992) Neurolin a cell surface glycoprotein that is re-expressed during retinal axonal regeneration. J. Cell Biol., 117:863-875.

Peters, A., Palay, S.L, and Webster, H. de F. (1991) The Fine Structure of the Nervous System. Oxford University Press, New York.

Raff, M.C., Abney, E.R., Cohen, J., Lindsay, R., and Noble, M. (1983) Two types of astrocytes in cultures of developing rat white matter: Differences in morphology, surface gangliosides, and growth characteristics. J. Neurosci., 3:1289-1300.

Remahl, S. and Hildebrand, C. (1990) Relations between axons and oligodendroglial cells during initial myelination. II. The individual axon. J. Neurocytol., 19:883-898.

Schneider-Schaulies, J, von Brunn, A., and Schachner, M. (1990) Recombinant peripheral myelin protein $\mathrm{P0}$ confers both adhesion and neurite outgrowth-promoting properties. J. Neurosci. Res., 27:286297.

Schliess, F. and Stoffel, W. (1991) Evolution of the myelin integral membrane proteins of the central nervous system. Biol. Chem.HoppeSeyler, 372:865-874.

Schwab, M.E. and Caroni, P. (1988) Oligodendrocytes and CNS myelin are nonpermissive substrates for neurite growth and fibroblast spreading in vitro. $J$. Neurosci., 8:2381-2393.

Seilheimer, B, and Schachner, M. (1988) Studies of adhesion molecules mediating interactions between cells of peripheral nervous system indicate a major role for $L 1$ in mediating sensory neuron growth on Schwann cells in culture. J. Cell Biol., 107:341-351.

Skene, J.H.P. (1989) Axonal growth-associated proteins. Annu. Rev. Neurosci., 12:127-156.

Sommer, I. and Schachner, M. (1981) Monoclonal antibodies (O1 to O4) to oligodendrocyte cell surfaces: An immunocytological study in the central nervous system. Dev. Biol., 83:311-327.

Sommer, I. and Schachner, M. (1982) Cells that are 04 antigen-posi- 
tive and $\mathrm{OL}$ antigen-negative differentiate into $\mathrm{O} 1$ antigen-positive oligodendrocytes Neurosei. Lett., 29:183-188.

Strobel, G. and Stuermer, C.A.O. (1991) Substrates for regenerating goldfish retinal axons in vivo. Soc. Neurosci. Abstr., 17:211.

Stuermer, C.A.O. (1991) Axon-glial cell interaction during optic nerve regeneration, Neurosci. Facts, 2:1,

Trotter; J. and Schachner, M. (1989) Cells positive for the O4 surface antigen isolated by cell sorting are able to differentiate into astrocytes or oligodendrocytes. Dev. Brain Res., 46:115-122.

Vanselow, J., Schwab, M.E., and Thanos, S. (1990) Responses of regenerating rat retinal ganglion cell axons to contacts with central nervous myelin in vitro. Eur. J. Neurosci, 2:121-125.

Vielmetter, J, and Stuermer, C.A.O. (1989) Goldfish retinal axons respond to position-specific properties of tectal cell membranes in vitro. Neuron, 2:1331-1339.

Vielmetter, J., Stolze, B., Bonhoeffer, F., and Stuermer, C.A.O. (1990) In vitro assay to test differential substrate affinities of growing axons and migratory cells. Exp. Brain Res., 81:283-287.

Vielmetter, J., Lottspeich, F, and Stuermer, C.A.O (1991) The monoclonal antibody E587 recognizes growing (new and regenerating) retinal axons in the goldfish retinotectal pathway. $J$. Neurosci, 11:3581-3593.

Wolburg, H. (1978) Growth and myelination of goldfish optic nerve fibers after retina regeneration and nerve crush. $Z$. Naturforsch., 33c:988 996. 